\title{
Impress: Improving Exposure Assessment Methodologies for Epidemiological Studies on Pesticides
}

DOI:

10.1564/v30_feb_05

\section{Document Version}

Accepted author manuscript

Link to publication record in Manchester Research Explorer

\section{Citation for published version (APA):}

Galea, K. S., Basinas, I., Cherrie, J. W., Fuhrimann, S., Harding, A-H., Jones, K., Kromhout, H., Ohlander, J., Povey, A., Sidek Ahmad, Z. N., Van Tongeren, M., \& Vermeulen, R. (2019). Impress: Improving Exposure Assessment Methodologies for Epidemiological Studies on Pesticides. Outlooks on Pest Management, 30(1), 1819. https://doi.org/10.1564/v30_feb_05

\section{Published in:}

Outlooks on Pest Management

\section{Citing this paper}

Please note that where the full-text provided on Manchester Research Explorer is the Author Accepted Manuscript or Proof version this may differ from the final Published version. If citing, it is advised that you check and use the publisher's definitive version.

\section{General rights}

Copyright and moral rights for the publications made accessible in the Research Explorer are retained by the authors and/or other copyright owners and it is a condition of accessing publications that users recognise and abide by the legal requirements associated with these rights.

\section{Takedown policy}

If you believe that this document breaches copyright please refer to the University of Manchester's Takedown Procedures [http://man.ac.uk/04Y6Bo] or contact uml.scholarlycommunications@manchester.ac.uk providing relevant details, so we can investigate your claim.

\section{OPEN ACCESS}




\title{
IMPRESS: IMPROVING EXPOSURE ASSESSMENT METHODOLOGIES FOR EPIDEMIOLOGICAL STUDIES ON PESTICIDES
}

\author{
Karen S. Galea', Ioannis Basinas', John W. Cherrie ${ }^{1,2}$, Samuel Fuhrimann ${ }^{3}$, Anne-Helen Harding ${ }^{4}$, Kate Jones ${ }^{4}$, \\ Hans Kromhout ${ }^{3}$, Johan Ohlander ${ }^{3}$, Andrew Povey ${ }^{5}$, Zulkhairul Naim Sidek Ahmad ${ }^{5}$, Martie van Tongeren and \\ Roel Vermeulen ${ }^{3}$; ' Centre for Human Exposure Science, Institute of Occupational Medicine, Edinburgh, EHI 4 \\ 4AP, UK; ${ }^{2}$ Heriot Watt University, Institute of Biological Chemistry, Biophysics and Bioengineering, Edinburgh \\ EHI 4 4AS, UK; ${ }^{3}$ Institute for Risk Assessment Sciences, Utrecht University, 3584 CM, The Netherlands; ${ }^{4}$ Health \\ \& Safety Laboratory, Harpur Hill, Buxton, SK 17 9JN, UK; ${ }^{5}$ Centre for Occupational and Environmental Health, \\ School of Health Sciences, Faculty of Biology, Medicine and Health, University of Manchester, Manchester \\ Academic Health Centre, MI3 9PL, UK
}

Authors listed alphabetically after first author

\begin{abstract}
This article introduces 'IMPRESS: Improving exposure assessment methodologies for epidemiological studies on pesticides', a new research project focussed on better understanding the performance of exposure assessment methodologies in pesticide epidemiology studies.
\end{abstract}

Keywords: epidemiology, pesticide exposure, exposure assessment

Exposure to certain pesticides is suspected to result in several chronic diseases such as cancers, reproductive effects (e.g. reduced semen quality, low birth weight) and Parkinson's disease. Studying chronic health diseases requires the assessment of historical exposures. However, exposure measurement data are rarely available. Therefore, assessment of historical exposures frequently needs to be based on self-reported information such as a person's job title, duration of employment, and/or whether they were ever exposed (yes/no) to pesticides or registered data like spray calendars. Naturally, such exposure measures suffer from some limitations (e.g. the ability of a person to remember their exposure history over a long time-period), which may affect the conclusions of a study. The large number of pesticides and pesticide mixtures involved, and the seasonality and broad range of characteristics regarding their application and use further complicates matters. With an increasing number of studies on occupational exposure to pesticides conducted each year, bias associated with respective exposure assessment methods may aggregate over time leading to potentially spurious associations or associations going undetected. Understanding the performance of the applied surrogate measures in exposure assessment is therefore important to allow proper evaluation of the involved risks.

The IMPRESS 'Improving exposure assessment methodologies for epidemiological studies on pesticides' project aims to understand better how well the existing methods of exposure assessment for pesticides perform when applied within epide- miological studies (i.e. studies looking to identify the causes of health effects within a human study population) of chronic health outcomes. IMPRESS is funded by the European Crop Protection Association (ECPA) and involves researchers from the Institute of Occupational Medicine (IOM), the Health and Safety Laboratory (HSL) and the University of Manchester in the UK as well as the Institute of Risk Assessment Science (IRAS) from the University of Utrecht in the Netherlands. In addition, the project has convened an independent Advisory Board, whose role is to provide advice to the project team on scientific quality and transparency regarding the research, its progress, and publication of the results.

This ongoing 4-year project, which started in September 2017, is split into four key activities and will involve the collection of data and biomonitoring samples from pesticide applicators working in the UK, Ethiopia and Malaysia.

Activity 1 aims to identify the most important and commonly used exposure assessment methods in occupational epidemiological research by reviewing available scientific literature systematically.

Activity 2 aims to evaluate the ability of workers to remember their pesticide exposure history. This will be achieved by comparing responses between the same questionnaires administered now and several years ago. Professional applicators and farmers from the UK and Ethiopia will participate in this activity.

In Activity 3, the adequacy of previously established mathematical models that can be used to estimate the exposure of workers to pesticides will be evaluated. For this, the questionnaire information on pesticide usage collected from UK, Ethiopian and Malaysian workers will be compared with the results from measurements of exposure in urine samples collected from the same workers. The results of these comparisons will be used to modify and improve the performance of the mathematical models.

In the fourth and final activity, the performance of some of the most important methods of exposure assessment identified in Activity 1 as well as of the improved mathematical models from Activity 3 will be assessed in a risk analyses. A range of different work populations will be used in this study. 
The IMPRESS team consider that the project results will be of importance to scientific and regulatory communities, as they will help inform future research regarding the preferred and most reliable exposure assessment methods to be applied in epidemiology studies focussed on pesticides.

Visit the project website for further information and updates on the project progress, http://www.impress-project.org/

Karen S. Galea is Head of the Exposure Science Section at the Institute of Occupational Medicine (IOM), Edinburgh. She has nearly 20 years' experience as a human exposure scientist, and has led a range of research and consultancy projects focussed on occupational, residential and consumer exposure. She is the Principal Investigator of the IMPRESS project.

loannis Basinas is a Senior Scientist at the IOM in Edinburgh. His research interests focus on the establishment and application of improved methods for quantitative exposure assessment based on statistical and mathematical modelling approaches. loannis has substantial experience in the assessment of exposure to organic dusts and the related health risks. Previously he was responsible for one of the largest exposure assessment studies on personal bio-aerosol exposures of farmers.

John W. Cherrie is Professor of Human Health at Heriot Watt University and Principal Scientist at the IOM in Edinburgh. He has been a member of the Advisory Committee on Pesticides and is currently a member of the HSE Workplace Health Expert Committee and the Industrial Injuries Advisory Council. John's research is concerned with understanding the links between human health and exposure to chemicals, pesticides, asbestos, air pollution and other risk factors. He is also interested in improving occupational and environmental exposure assessment for epidemiological studies of neurodegenerative disease and modelling exposure to welding fume.

Samuel Fuhrimann is a Post-Doctoral fellow at the Institute for Risk Assessment Sciences at Utrecht University in the Netherlands. His research focus is on risk assessment of microbial and chemical environmental contamination in the context of agricultural systems in low- and middle-income countries with a specific focus on epidemiological transition. His current research projects are mainly focusing on risk assessments related to pesticide use in Uganda and Costa Rica (PESTROP project), South Africa (CapSA project), and Ethiopia, Malaysia and the UK (IMPRESS project).

Anne-Helen Harding is an epidemiologist/statistician with the HSE, where she has worked for over 10 years. She is Principal Investigator on two cohort studies: the Prospective Investigation of Pesticide Applicators' Health (PIPAH) Study and the GB Asbestos Workers Survey. In addition Anne-Helen provides statistical support to colleagues across the organisation and is the Epidemiology Team Technical Lead.Anne-Helen is an expert member of a National Research Ethics Committee and a Member of the UK Government Statistical Group.
Kate Jones is an analytical chemist working as the Team Lead for HSL's Biological Monitoring team. She has wide experience and expertise in the biological monitoring of organic compounds and particularly pesticides. She has also overseen a number of human volunteer studies involving pesticides. She is currently Chair of both the Royal Society of Chemistry's Toxicology group and the International Commission on Occupational Health's scientific committee on Occupational Toxicology.

Hans Kromhout is an international authority on occupational and environmental exposure assessment and epidemiology based at the Institute for Risk Assessment Sciences at Utrecht University in the Netherlands. His work has covered the health effects of chemical and physical agents in the workplace and general environment. He has been responsible for large international studies in among others the asphalt industry, the rubber manufacturing industry, the industrial minerals industry, the health sector and within agriculture and community based studies on cancer, respiratory diseases, neurodegenerative diseases and reproductive health effects.

Johan Ohlander is a Post-Doctoral fellow at the Institute for Risk Assessment Sciences at Utrecht University in the Netherlands. He has several years of experience in planning, executing and analyzing epidemiological studies, particularly focusing on occupational risk factors in the automotive industry. As part of his work on the IMPRESS project he has conducted a systematic review of exposure assessment methods used in studies of occupational pesticide exposure.

Andrew Povey is a Reader in Molecular Epidemiology at the University of Manchester. He has been a member of the Advisory Committee on Pesticides and is currently a member of the Committee Mutagenicity of Chemicals in Food, Consumer Products and the Environment. He has co-authored more than 110 peer-reviewed papers.

Zulkhairul Naim Sidek Ahmad is a PhD student at the University of Manchester The focus of his research is organophosphate exposure and general and reproductive health in farmers in Sabah, Malaysia.

Martie van Tongeren is Professor of Occupational and Environmental Health, at the University of Manchester as well as Principal Scientist at the IOM, Edinburgh. He has over 25 years of experience in exposure assessment for epidemiology and risk assessment, mainly in the occupational field, but also in the area of consumer/residential exposure and has co-authored nearly 120 peerreviewed papers.

Roel Vermeulen is a Professor of Environmental Epidemiology and Exposome Science at the Institute for Risk Assessment Sciences at Utrecht University in the Netherlands. He has a background in environmental risk factors for cancer, asthma and neurological diseases with a particular focus on exposure assessment. He uses novel sensor, molecular and statistical approaches to assist in the characterisation of environmental exposures. He is the Principal Investigator of the national research project on pesticide exposure of residents.

\section{Similar articles that appeared in Outlooks on Pest Management include - 2016 27(2) 70; 2017 28(2) $86 ; 2018$ 29(I) 43}

